\title{
Exploring Non-finite Verbs of the English Language
}

\author{
In-Chul Lee ${ }^{1}$, Mun-Koo Kang ${ }^{2}$ \\ ${ }^{1}$ Student, 32588 Kongju National University, 56 Gongjudaehak-ro, Gongju-si, Chungnam-do, South \\ Korea,pfe6917@hanmail.net \\ ${ }^{2}$ Professor, 32588 Kongju National University, 56 Gongjudaehak-ro, Gongju-si, Chungnam-do, South \\ Korea, kangmunkoo@hanmail.net
}

Corresponding author: Mun-Koo Kang

\begin{abstract}
Non-finite verbs such as infinitive, gerund, and participle are a type of tense that is widely used in written and spoken languages, and are actively used to convey the differences between their meanings in various texts. This paper evaluates that the study of non-finite verbs which frequently appears in school grammar readings) should be worthwhile), and a study conducted) on clauses that encompass to-infective, bare infinitive, -ing participle, and past participle. Existing studies had a limitation in that they did not comprehensively review the non-finite clause itself, focusing on the method of only teaching the tense. Based on the results of the study, it was intended to suggest the direction that English teachers should pursue for efficient learning of infinitive, gerund, and participle for learners in the future. Therefore, in this study, the theoretical framework of the literature research method was used for reviewing and analyzing it as a whole to analyze the characteristics, forms and functions of the non-finite clause, and the relationship between the tense and the aspect. In particular we focused on analyzing the non-finite clause by comparing the infinitive, gerund, and participle, while focusing on the fact that non-tensed verbs forms are related to each other.
\end{abstract}

Keywords: Non-finite Verb, Non-finite Clause, Infinitive, Present Participle, Past Participle

\section{Introduction}

\subsection{Definition of Terms}

Language and grammar changes over time. However, most grammar books at home and abroad do not reflect this change in language and remain in the category of prescriptive grammar. Accordingly, grammar education has not deviated from the category of 'right grammar', focusing on fragmentary grammar elements. It is time to need a descriptive grammar that reflects changes in actual language and grammar.

In grammar learning, it is necessary to have an integrated view of how the components of grammar interact with each other, not just to understand each element of grammar individually and fragmentarily. That way, we will be able to explain English grammar items in the field of English grammar education that could not be explained with the existing prescriptive grammar.

When teaching sentence structure in Korean school sites, there is a tendency to divide into clauses (noun clauses, relative pronoun clauses, adverb clauses) and phrases (to-infinitive, gerund, particles) [1]. Currently, many schools are learning the grammar elements of to-infinitive, gerund, and particles with their respective disconnected items. This method requires students to learn the usage and use of 
to-infinitive, gerund, and particles respectively, so more time and effort are required to understand them. Learning about these arbitrary and diverse individual items makes L2 language learners feel very difficult.

Celce-Murcia \& Larsen-Freeman and Bas Aarts regarded these clauses and phrases as one great other clause within a sentence. Celce-Murcia \& Larsen-Freeman described this as "clausal complementation" and Bas Aarts described it as "Non-finite Subordinate Clause".

In this study, Celce-Murcia \& Larsen-Freeman expanded the concept of "clause" and explained "full clausal that-complements with a tense," "subjuctive complements without a tense," "infinitives," "gerunds," "noun-participle constructions" as "complementation". In this study, first of all, we will examine the concept of "clause" by Celce-Murcia \& Larsen-Freeman, and analyze the definition and difference of terms in the finite clauses and the non-finite clauses based on Bas Aarts' progressive grammar.

The distinction between finite clauses and non-finite clauses is generally determined by the presence or absence of a tense. It seems that a considerable amount of time has passed for those expressed as so-called quasi-verbs and phrases in the existing traditional grammar to become clauses in modern English grammar.

If we understand the grammar items such as to-infinite, gerund, and particles which were described as quasi-verb in the existing grammar as an non-finite clause, we will be able to teach grammar elements that were difficult to explain in school grammar in an integrated way.

\subsection{The Form of Complements}

\subsubsection{That-complements}

Celce-Murcia \& Larsen-Freeman explained "complements" means elements or adjectives necessary to supplement the meaning of a verb and they are different from adjuncts[2].

1) a. John believed that Jill was coming

b. John almost believed that Jill was coming.

In 1)-a, the verb believe needs a phrase equivalent to a noun as an object. At this time, NP can be placed in the position of the object or an embedded complement clause can be placed. However, almost in 1)-b is not a structurally essential component, but an optional adverb phrase.

Celce-Murcia \& Larsen-Freeman described clauses containing a verbal element with an assumed subject or an expressed subject as "clausal complements" and classified them into five types. These are "full clausal that-complements with a tense," "subjuctive complements without a tesnse," "infinitives," "gerunds," "noun-participle constructions," and these types tend to be used with certain verbs.

Tensed that-clauses are the most common type of clausal complement. Look at the sentences below

2) a. Scientists claim [that the globe is getting warmer].

b. [That the globe is getting warmer] is claimed by scientists.

3) a. We long expected [that nothing worthwhile would come from our effort].

b. [That nothing worthwhile would come from our effort] was long expected by us.

4) a. People generally know [that bears don't make good pets].

b. [That bears don't make good pets] is generally known (by people).

The data enclosed in parentheses of the sentences a in 2)-4) changed from the direct object of the active type to the passive type of $b$, and appeared as the subject, which is another location where NP occurs. These subordinate clauses should be regarded as essentially nouns, and can be considered to form an integral part as they are embedded in larger, independent clauses. Celce-Murcia \& LarsenFreeman called "that" in this case as a "complementizer" and regarded it as a signal leading to a complement clause. Verbs that allow "that-complements with a tense" as an object are: believe, claim, 
expect, know, assume, discover, explain, find, find out, imagine, learn, perceive, point out, promise, prove, see, show, think, understand.

\subsubsection{Infinitive Complements}

Expanding the concept of "clause" somewhat to include subject-verb sequences without a tense, infinitives are a common type of clause without tense. Celce-Murcia \& Larsen-Freeman classified Infinitive complements into five subtypes: "believe type," "advise type," "attempt type," "want type," "let type".

5) a. The students believed [their professor to be amazing].

b. The citizens imagined [the politician to have led an honest life].

The parenthesis part of 5) has no tense. When asked if infinitives can be viewed as clauses even without tense, Celce-Murcia \& Larsen-Freeman explains that it should be viewed as clauses because it contains subjects and verbs.

6) a. *The students believe [their professor to can do almost anything].

b. The students believe [their professor to be able to do good research].

c. The students believe [their professor to be correcting their homework].

d. The students believe [their professor to have been lecturing too much lately].

You cannot use infinitives with modal verbs as in 6)-a, but you can use 6)-c for progressive and 6)-d for perfect progressive infinitives.

7) a. We advised the children to play baseball outside.

b. The police officer ordered my friend to move his car.

8) a. We advised them to play baseball outside.

b. The police officer ordered him to move his car.

In the examples in 7 and 8), the main clause has actual objects (the children, my friend, the item, him), and if so, you need to know what the rest of the infinitives are. The rest of the infinitives are supplements to this object.

Also, if you want to call all infinitive a clause, you need to know what constitutes the subject of this infinitive. We call these empty elements of the subject part PRO; this is not a lexical pronoun but does not appear on the surface. It simply indicates that some NP within the main clause function semantically as the subject of the supplementary clause. These types of verbs are allow, cause, force, help, permit, persuade, and urge.

The third type of infinitive is the subject control type. This control is a type in which the subject, not the object of the principal clause, controls the subject of the $t o$-infinitive. In this type, the subject of the principalclause controls the identity of an to-infinitival subject called PRO.

9) a. The driver attempted to avoid the ice on the road.

b. Bears tend to eat voraciously in the spring.

In the example sentence of 9), to-infinitive is not a direct object for attempted or tend. These types of verbs are begin, continue, decide, fail, forger, manage, offer, proceed, promise, refuse, regret remember start, try, and vow.

A verb in the main clause that allows infinitives as complements allows the selection of the subject or object of the principal clause while providing a subject to the to-infinitive. This object is clearly expressed, and the subject of the to-infinitive is expressed with the for.

10) a. I want to refinish the furniture.

b. I want (for) him to refinish the furniture.

11) a. She intends to clean the house.

b. Sje intends (for) him to clean the house.

In the examples 10) and 11), Celce-Murcia \& Larsen-Freeman treated the preposition for as acting as a 
"complementizer that" with tense. In this case, it was explained that if there is a "for-complementizer", the subject of infinitive is clear, and if there is no "for-complementizer", the subject of the principal clause becomes the subject of the to-infinitive and can be expressed as PRO. These types of verbs want, expect, hope, arrange, desire, expect, hate, hope, intend, like, love, plan, and prefer.

The last important type of infinitive is called the bare-stem infinitive.

12) a. The teacher let the students go home early.

b. We saw our friend leave the station.

In the example 12), bare-stem infinitives are not the direct objects of the main verbs but clausal complements of the main-clause verb. In this case, to did not appear, but the position of the AUX indicates "tenseless" with [-imper]. These types of verbs are feel, have, hear, help, make, observe and watch.

\subsubsection{Gerund Complements}

Just as that-clauses and infinitives serve as verbal complements, -ing complement (gerund) can also serve as verbal complements.

13) a. Fred disliked [making phone calls to John].

b. Mary preferred [doing other things with her time].

In Example 13) above, the parentheses have the same structure as the subject-control infinitives as the attempt examined in infinitive. The logical subject in parentheses is the same as the subject of the entire sentence. That is, in the example sentence of 14) below, it can be seen that the subject of gerund is the same as the subject of the entire sentence.

14) a. [(Fred) making phone calls to John] $\rightarrow$ Fred make phone calls to John.

b. [(Mary) doing other things with her time] $\rightarrow$ Mary did other things with her time.

At this time, the unspecified subject of gerund is the same role as "the PRO-type subject" identified in infinitives. Gerund can also have perfect and progressive forms, as shown in 15).

15) a. having made phone calls to John

b. having been making phone calls to John.

Gerund can have a subject in the form of [NP+possessive morpheme or a possessive determiner]. The verbs having the gerund complements are admit, appreciate, avoid, begin, continue, defend, deny, enjoy, feel, finish, forget, hate, hear, like, love, prefer, quit, recall, regret, remember, resume, risk, see, smell, start, stop, and try.

\subsubsection{The Subject-participle Complement}

The subject-participle complement has the same surface appearance as the gerund, but the gerund has a possessive form as the subject, but the subject-participle complement has NP or object pronoun in its place. It functions like the -ing participle clause, which Bas Aarts classified as non-finite clauses.

16) a. He doesn't want [his employees sitting around with nothing to do].

b. I watched [the ice melting in the sun].

c. The teacher had [the students drawing trees] yesterday.

In the sentence of 16), the -ing form in parentheses has no tense and the entire parenthesis functions as a noun object. This type of clause is frequently used as the object of the preposition with, as in the example in 17).

17) a. With [the employees sitting around with nothing to do], the firm won't survive.

b. With [the ice melting in the sun], there won't be any cold drinks left.

c. With [the students drawing trees], the kindergarten teacher could relax.

Verbs with the subject-participle complement are discover, feel, hate, have, hear, like, love, observe, prefer, recall, remember, see, and watch. 
So far, we have looked at the role of Celce-Murcia \& Larsen-Freeman's complementation. Next, we will consider the finite clauses and non-finite clauses of Bas Aarts.

\subsection{Finite Clauses and Non-finite Caluses}

\subsubsection{Finite Clauses}

The finite clause generally includes a verb to which inflection is applied according to the person system and number appearing in the subject, but there are no exceptions. The clause with a tense is a finite clause, but it is difficult to say that every finite clause has a tense [3]. For example, subjunctive clauses and imperative clauses are not called non-finite clauses even without a tense.

In the example below, the verb 'open' has no tense.

18) Open the door.

Subordination is a grammatical phenomenon involving an arrangement of two or more units (words, phrases, clauses) that are in a hierarchy structure. Subordinate clauses are licensed by verbs. A clause that is not subordinate to another clause is called a main or matrix clause and it means a clause including a dependent clause. The main clause is called 'main clause' or 'matrix clause'. The subordinate clause has its own subject and predicate, and has its own direct object, indirect object, and complement licensed by the verb. Just as the sentence of 19) has two subordinate clauses, the subordinate clause can be more subordinate clauses to more layers.

19) [main/matrix clause They are describing [clause 2 that they think [clause 3 that the person is jealous]]].

In 2), 'clause 2' is the direct object approved by the verb DESCRIBE, and 'clause 3' is the direct object approved by the verb THINK.

The subordinate clause is led by 'subordinating conjunctions' that function as a marker of subordination. In English, there are three subordinate conjunctions for finite clauses, and 'that', 'whether', and 'if' are subordinate conjunctions of finite clauses, while 'for' is the subordinate conjunctions of non-finite clauses.

There are three subordinate clauses in English: content clauses, comparative clauses, and relative clauses. The first type of subordinate clauses is content clauses, which performs various functions of Complement of a noun, an adjective, and a preposition. There are three types of "content clauses: declarative content clauses, interrogative content clauses, and exclamative content clauses." The second type of subordinate clauses, the comparison clause, has to be divided into several to explain the comparison. First, we need to think about the comparison between scalar types such as 'cold' and 'young' that can modified by the expression 'very' and non-scalar types such as 'same' and 'different'. Second, we have to think about equal comparison and non-equal comparison, and the non-equal expression is divided into comparison of superiority and comparison of inferiority.

[Table 1] The Scalar/Non-scalar and Equality/Inequality Contrasts [4]

\begin{tabular}{|c|c|c|c|}
\hline & equality & & inequality \\
\hline \multirow{2}{*}{ scalar } & \multirow{2}{*}{$\begin{array}{l}\text { (a) You can be as personal [ } \mathrm{PP} \text { as [clause } \\
\text { you like]]. }\end{array}$} & $\begin{array}{l}\text { superiorit } \\
\mathrm{y}\end{array}$ & $\begin{array}{l}\text { (b) Well your memory is better [PP than } \\
\text { [clause mine is]]. }\end{array}$ \\
\hline & & inferiority & $\begin{array}{l}\text { (c) Leaf mould is less acid [pp than [clause } \\
\text { peat]]. }\end{array}$ \\
\hline
\end{tabular}

Non- $\quad$ (d) The stretch of tablecloth in front

scalar of my companion looked same [PP as [clause mine did]].

(e) The total flow from the well was different [PP than [clause it was before the leak was found]].

The third type of subordinate clauses are relative clauses. They provide additional information about 
the Head noun called antecedent. A relative pronoun is a noun, so a simple relational phase is a noun phrase. The relative pronoun serves as the Head in the relative pronoun phrase. Bas Aarts distinguished words such as when, where, while, etc. with prepositions. In 20) relativized clause(when) are intransitive prepositions heading PPs.

20) In the period [clause [PP when] he was writing in the fifties _ ], he was reaching the climax of his career.

Relative clauses are sometimes non-finite. Non-finite relative clauses are considered incomplete finite clauses. It is believed that 'who was' in 21) was omitted and 'which is' was omitted in 22) in the relative clause.

21) [NP The young lady [clause sitting next to you]] was wearing the T-shirt.

22) The Mansion House itself is [NP a fine neoclassical building [clause sustained by a portico of six Corinthian columns]].

Let's look at another type of relative clauses. Free relative clauses syntactically do not have an explicit Head expressed by the relative clause. Free relative clauses function as Subject, Direct Object, and Prepositional Complement in the main clause. Free relative clauses function grammatically as noun phrases, but they look like clauses because they have verbs with a tense. Look at the sentences 23 ) and 24). The sentence 23) is interpreted as 24).

23) The point is you can do [what you like _].

24) The point is you can do that which you like.

\subsubsection{Non-finite Clauses}

The non-finite clause must appear only as a subordinate clause and does not include verbs with tense. Examples are shown in the table below.

[Table 2] Types of Non-finite Clauses [4]

\begin{tabular}{lc}
\hline Types of Non-finite Clause & Examples \\
\hline to-infinitive clause & Would anybody like to eat? \\
\hline bare infinitive clause & They can stop at any point. \\
\hline -ing participle clause & We are selling them. \\
\hline past participle clause & So we have prayed our part in the history of cricket. \\
\hline & She was delayed by train difficulties. \\
\end{tabular}

\section{Contents}

\subsection{Form and Function of Non-finite Clauses}

According to Bas Aarts, as explained in the previous section, there are four types of non-finite clauses. They are "to-infinitive clauses, bare infinitive, -ing participle clause and past participle clause." First, to-infinitive clauses work as a subject, a complement clause, a direct object, an adjunct 
and a complement of the subject-related predicate. Second, bare infinitive clauses function as a direct object, a complement clause, and a complement of the subject-related predicate. Third, -ing particle clauses function as a subject, a complement clause, a direct object, an adjunct, a complement of the subject-related predicate, object-related predicative complement. Fourth, past participle clauses function as a direct object, an adjunct and a complement clause. Now let's take a closer look at these four types of non-finite clauses with examples.

\subsubsection{To-infinitive Clauses}

The function of the to-infinitive clause is a subject, a complement clause, a direct object, an adjunct, and a complement of the subject-related predicate [4][5].

First, let's look at the to-infinitive clause that functions as a subject. It can be omitted when the subject of the to-infinitive clause represents general people.

25) [clause $\varnothing$ To make moral judgements] is to be judgemental.

In order to represent the subject, the subordinator for is used, which is completely different from the case where it is regarded as a preposition in the existing English grammar.

26) [clause For those in the third age to want a job] is to go back on the system.

In 26) above, for is used as a subordinate conjunction to lead the semantic subject.

In addition, to-infinitive clauses can function as a direct object. As the example in 27) shows, 'to alter the scenario very slightly' is a direct object, 'you' is a semantic subject and 'for' is a subordinate conjunction.

27) I just want [clause you to alter the scenario very slightly].

One thing to note here is that because the object of 'want' is not 'you' but 'to alter the scenario very slightly.' We cannot create a passive sentence with 'you' as the subject.

Next, we will find out about subject control. As shown in the example below, the subject, $I$, of the principal clause and the subject of the to-infinitive clause are the same. Therefore, it is not necessary to put the subject 'I' in front of the to-infinitive. This syntactic situation is called subject control in English grammar. Here, i, used as the letter below means that the subjects are the same as each other.

28) Ii hesitate [clause Øi to mention this].

Next, look at the indirect object control. As shown in the example below, the to-infinitive clause does not have its own subject. However, the indirect object can be interpreted as the implicit subject of the subordinate clause. Therefore, it can be said that the subject of the to-infinitive clause is controlled by 'them' which is an indirect object.

29) They told [NP themi] [clause $\emptyset_{i}$ to gather round water holes].

Direct object control refers to a case in which the direct object of the main verb is the subject of an to-infinitive. As in the example below, the direct object is regarded as the implied subject of the toinfinitive clause. In other words, 'the UN' in 30) performs the role of a direct object, and here 'toinfinitive clause' is a complement clause.

30) The Americans persuaded [NP the UN] $i$ [clause Øi to impose the deadline].

However, as shown in 31) and 32) below, 'there' or dummy 'it' cannot be placed right behind PERSUADE.

31) *Sarah persuaded there to be a meeting next week.

32) *Leon persuaded it to rain on Wednesday.

So far, we've looked at control of the subject or object and then we'll look at raising.

As shown in example 33) below, the verb that causes the subject of the subordinate clause to rise as the direct object of the main clause is called 'raising-to-object verbs' and the direct object of 'the rising-to-object verb' is called 'raised object.' It can be said that 'this raised object' breaks the barrier between the clause and the clause. Also, 'a raised object' is given a semantic role from a semantic 
contextual verb (in the example below, sell in the to-infinitive clause) within a subordinate clause, not the verb (in the example sentence below, intend) that licenses it

33) He intended [NP them] $i$ [clause Øi to sell only 50 per cent of Test matches to satellite television].

Next, look at 'raising-to-subject.' In the example below, SEEM can be called a 'raising-to-subject verb' because the subject of 'look' is moved from the subordinate clause to the subject of the main clause [4].

34) [NP The author] i seems [clause Øi to look on the past with a kind of maturity].

Raised subjects are given semantic roles from the semantic contextual verb in a subordinate clause, not the verb that follows it (in the case of Example 34), look in the to-infinitive clause).

\subsubsection{Bare Infinitive Clauses}

Bare infinitive clauses function as a complement clause, a direct object and a subject-related predicative complement. First, look at the bare infinitive clauses that function as a direct object. As shown in example 35) below, the subordinate clause that has its own subject functions as a direct object.

35) "She entertained people like Melvyn Bragg, Cherie and Tony Blair and had [clause the Queen open the refurbishment]," said the source.

The noun phrase (the Queen) located behind the verb is not analyzed as a direct object because it cannot be used as a subject of a passive clause [4].

36) * The queen had opened the refurbishment.

In the case of 'HEAR, HELP, MAKE, NOTICE, OBSERVE, SEE', to is added and conversion to the passive form becomes possible.

37) Alcohol makes you feel invincible when you are most vulnerable.

$\rightarrow$ You are made to feel invincible when you are most vulnerable by alcohol.

Next, look at the bare infinitive clauses that function as complement clauses. As shown in Example

38 ), the auxiliary verbs allow the bare infinitive clauses to come behind itself. At this time, The vare infinitive clauses serve as the complement clauses.

39) Shei can [clause $\varnothing_{i}$ come with Anna and Peter].

Since the subject of the subordinate clause is moved to the subject of the principal clause, the bare infinitive clauses do not have their own explicit subject. Therefore, it is understood that the implied subject of the subordinate clause is the same as the subject of the principal clause.

Also, the bare infinitive verb may appear as another auxiliary verb as in 40).

40) You $i$ must [clause $Ø i$ have been a very fast driver].

In the case of the bare infinitive clauses which work as a complement of the subject-related predicate, as shown in example 41), the bare infinitive clauses can work as a complement of the subject-related predicate, only after the verb 'BE.' The bare infinitive clauses do not have their own subject. However, it is understood that the implicit subject is the same as the noun phrase in the main clause[6].

41) What you $i$ do is [clause $\emptyset_{i}$ wear it like that].

\subsection{3 -Ing Particle Clauses}

-Ing particle clauses function as a subject, a direct object, a complement clause, a complement of the subject-related predicate, a complement of object-related predicate, and an adjunct.

First, look at the -ing particle clauses that function as subjects. -Ing particle clauses may or may not have their own subject, as shown in examples 42) and 43) below. In the latter case, the implicit subject can be found by analogy or has a general subject through the context ('for people to get aid 
through')[7].

42) [clause Thurn and Taxis having the wrongful monopoly of the European postal system in the past] caused Trystero to claim to have been disinherited.

43) [clause $\varnothing$ Getting aid through] is a nightmare.

Let's look at the -ing participle clauses that function as direct objects. -Ing participle clause can work as a direct object that has or does not have its own subject. As in example 44), the implied subject of the subordinate clause is interpreted as the same as the subject of the main clause, and as in example 45), the implicit subject of the subordinate clause that cannot be found from the main clause is interpreted as a general person.

44) I $i$ remember [clause $\varnothing i$ passing out in Sainsbury's once].

45) This role of corporation shouter is a long and honourable one, though probably not dating back to the days of Lord Reith, who discouraged [clause $\varnothing$ shouting at politicians], even by reporters in evening dress.

In the case of RECOMMEND [clause NP/NP's -ing participle...] in 46), it has a syntactically important meaning, and a general noun phrase or genitive noun phrase comes as the subject of the -ing participle clause. This genitival subject does not appear often and is used in formal situations. The genitive inflection -'s can be removed if there is no perceptible difference in meaning. The noun phrases in the subordinate clauses (Jill, Britain's in the case of examples) are not regarded as direct objects of each verb (recommend, accept in the case of examples).

46) The administrators recommended [clause Jill carrying out this project].

47) Other community countries would accept [clause Britain's delaying a decision on joining a single currency until after the next election].

What should be noted here is that Jill cannot be the subject of a passive clause, as shown in example 48) below. This is because noun phrases in the subordinate clause cannot be the subject of a passive clause.

48) *Jill was recommended carrying out this project by the administrators.

However, as in example 49) below, the entire -ing participle can be the subject of a passive clause.

49) [Jill carrying out this project] was recommended by the administrators.

Next, -ing particle clause works as a complement clause. In the example of 50), -ing particle clause works as a complement clause of 'from'.

50) The state prevented you from teaching.

The sentence of 50) is analyzed as 51), where 'you' is 'the raised object' of the verb and 'from teaching' serves as a supplementary word for the verb. That is, in 51), the -ing participle clause serves as a complement for the preposition 'from'.

51) The state prevented [NP you $] i$ [pp from [clause $\varnothing_{i}$ teatching]].

-ing participle clauses have a subject as in 52) or function a subject-related predicative complement as in 53).

52) This is [clause her being executrix to Pierce's will].

53) The difficulty is [clause $\emptyset$ producing the quantity we may need at exactly the right moment].

-ing particles play the role of Object-related Predictive Complement, as in 54). Implicit subject cannot be inferred within the main clause.

54) The Israelis call [NP that] [clause $\varnothing$ restoring the army's deterrent power].

-ing particles also play a role of as Adjuncts. It functions as additional words that does not serve as necessary components of the sentence but provides additional contextual information. 55) is interpreted as 'while I was answering the best I could.' In 56), -ing participle clause has no subject, but an analogy is possible from the main clause. It is interpreted as 'while I was waiting by the door.'

55) We muddled through, [clause him asking questions], [clause me answering the best I could]. 
56) Every Tuesday $\mathrm{I}_{\mathrm{i}}$ stood there, [clause $\emptyset_{i}$ waiting by the door].

\subsubsection{Past Participle Clauses}

Past participle clauses work as a direct object, a complement clause, and an adjunct.

First, let's look at the direct object function. As shown in 57) below, the subordinate clause is a passive form, and a by-clause can be added.

57) I had [clause my tonsils removed].

'My tonsils' is a semantic argument of REMOVE, not of the verb HAVE[7]. Therefore, 58) has the meaning of 'I brought about that my tonsils were removed' rather than 'I had my tonsils.' In the form discussed, the syntactic analysis is consistent with the semantic analysis.

58) *My tonsils were had been moved.

The sentence of 58) is an ungrammatical sentence. 'My tonsils' cannot be the subject of the main clause when converting to the passive form, because it is not the direct object of the main verb.

In the case of past participle clauses that function as complement clauses, the perfect modal HAVE is followed by a verb ending with -ed (some verbs are -(e)n), as shown in example 30) below.

59) Ii have [clause Øi informed the police of the theft].

Since the subject of the main clause plays a semantic role for INFORM in the subordinate clause, the aspectual auxiliary (have in 59) is regarded as a raising verb.

The past participle clause, which serves as an adjunct, can be used with a subject like 60) or without a subject like 61).

60) seven villagers were arrested, [clause their feet bound together with rope], and they hung upside down for hour.

61) [clause $\varnothing$ Dressed in civilian clothes] they gave the impression of being members of a rabble army.

\section{Conclusions}

The finite clause refers to a general clause that has a main verb that changes a tense, and a non-finite clause refers to a clause that has a verb that does not change the tense. Usually, the to-infinitive, gerund, and participles have been collectively called quasi-verbs because it is convenient to understand quasi-verbs as separate clauses in the past functionalist grammar. In other words, the structural functionalist grammar divides the clause into a finite clause and a non-finite clause, and the tense of the subordinate verb in the clause differs depending on the situation to be spoken, which may be the same as or different from the tense of the main clause verb.

We believe that summarizing these points as above is an appropriate attempt to conclude this study and hope that it will help us to have a better understanding of the English non-finite clause. In this study, in order to better understand non-finite clauses, infinitive, gerund, and participles were organized based on descriptive grammar. The limitation of this study is that when this grammar theory explanation is applied to classroom instruction, it is necessary to consider how the teaching method will be applied later. Based on descriptive grammar, the approach of understanding clauses as finite clauses and non-finite clauses and then understanding to-infinitive, gerund, and particles in non-finite clauses will be difficult to apply at the school site in Korea right now. It is hoped that the learning of to-infinitive, gerund, and particles can be efficiently related in the practical English grammar curriculum through future research incorporating teaching methods. 


\section{References}

[1] Uiseong Lee, Effective teaching method of English tense, Kangwon National University Graduate School of Education, Master's Thesis, (2000)

[2] Mi-young Lee, A Study on Understanding and Using English Tense, Graduate School of Korea National University of Education, Master's Thesis, (2000)

[3] Yong-gil Jeong, On the Classification of the Non-finite Clauses in English, Journal of Humanities, Seoul National University, (2015), Vol.29, pp.65-82

[4] Bas Aarts, Oxford Modern English Grammar, Oxford University Press, (2011)

[5] Eun-suk Jung, A study on the Grammatical Function and Meaning of To-infinitive, Dankook University, Master's Thesis, (1994)

[6] O. Jesperson, Essentials of English Grammar, Allen \& Unwin, (1933)

[7] R. Quirk, S. Greenbaum, G. Leech, J. Svartvik, A comprehensive Grammar of the English Language, Longman, (1985) 